\title{
Characterization of Student and Instructor Behaviors in CURE and Non-CURE Learning Environments: Implications for Non-Cognitive Student Outcomes
}

\author{
David Esparza, Amy E. Wagler, and Jeffrey T. Olimpo
}

The University of Texas at El Paso, Department of Biological Sciences, 500 W. University Ave, B226, Biology Bldg, El Paso TX 79968 USA

(desparza12@miners.utep.edu)

\begin{abstract}
Course-based undergraduate research experiences (CUREs) serve to increase student access to authentic scientific opportunities. Current evidence within the literature indicates that engagement in CUREs promotes students' science identity development, and affect ability to "think like a scientist." Despite the importance of these findings, few studies have examined the behaviors and interactions occurring within CURE and non-CURE settings and the impact of those behaviors on said student outcomes. To address these concerns, we conducted a mixed methods study to explore student and instructor behaviors in four CURE and four non-CURE introductory biology laboratory sections. Representative video data were collected in each section and coded using the Laboratory Observation Protocol for Undergraduate STEM. In addition, pre-/post-semester affective survey data were obtained from CURE $(\mathrm{n}=47)$ and non-CURE $(\mathrm{n}=64)$ participants. Results indicated that CURE students and instructors engaged in more interactive behaviors (e.g., one-on-one dialogue; questioning) than their non-CURE counterparts ( $\mathrm{p} \leq 0.005$ for all analyses), a finding confirmed by analyzing behavioral patterns via construction of partial correlation networks. Multiple regression analyses further revealed that student/instructor interactive behaviors and enrollment in a CURE were strong predictors of pre-/post-semester shifts in student motivation, science identity development, discovery-based learning, and collaboration.
\end{abstract}

Keywords: CURE assessment

\section{Mission, Review Process \& Disclaimer}

The Association for Biology Laboratory Education (ABLE) was founded in 1979 to promote information exchange among university and college educators actively concerned with teaching biology in a laboratory setting. The focus of ABLE is to improve the undergraduate biology laboratory experience by promoting the development and dissemination of interesting, innovative, and reliable laboratory exercises. For more information about ABLE, please visit http://www.ableweb.org/.

Advances in Biology Laboratory Education is the peer-reviewed publication of the conference of the Association for Biology Laboratory Education. Published articles and extended abstracts are evaluated and selected by a committee prior to presentation at the conference, peer-reviewed by participants at the conference, and edited by members of the ABLE Editorial Board. Published abstracts are evaluated and selected by a committee prior to presentation at the conference.

\section{Citing This Article}

Esparza D, Wagler AE, Olimpo JT. 2020. Characterization of student and instructor behaviors in CURE and non-CURE learning environments: implications for non-cognitive student outcomes. Article $67 \mathrm{In}$ : McMahon K, editor. Advances in biology laboratory education. Volume 41. Publication of the 41st Conference of the Association for Biology Laboratory Education (ABLE). https://doi.org/10.37590/able.v41.abs67

Compilation (C) 2020 by the Association for Biology Laboratory Education, ISBN 1-890444-17-0. All rights reserved. No part of this publication may be reproduced, stored in a retrieval system, or transmitted, in any form or by any means, electronic, mechanical, photocopying, recording, or otherwise, without the prior written permission of the copyright owner. 
ABLE strongly encourages individuals to use the exercises in this volume in their teaching program. If this exercise is used solely at one's own institution with no intent for profit, it is excluded from the preceding copyright restriction, unless otherwise noted on the copyright notice of the individual chapter in this volume. Proper credit to this publication must be included in your laboratory outline for each use; a sample citation is given above. 